\title{
Health inequalities and the welfare state
}

\author{
Else-Karin Grøholt ${ }^{1}$, Espen Dahl ${ }^{2}$ and Jon Ivar Elstad ${ }^{3}$ \\ ${ }^{1}$ Norwegian Institute of Public Health, Oslo, Norway \\ ${ }^{2}$ Oslo University College \\ ${ }^{3}$ NOVA - Norwegian Social Research, and Department of Sociology and Human Geography, University of Oslo \\ Korrespondanse: Else-Karin Grøholt, E-mail: else-karin.groholt@fhi.no
}

\begin{abstract}
This issue of the Norwegian Journal of Epidemiology is based on the research conference Health Inequalities and the Welfare State at the Soria Moria Conference Center in Oslo, Norway, October 10-11 2006. The main purpose of the conference was to support, stimulate, disseminate and contribute to research in Norway on social inequalities in health. Nine papers are included in this issue, in addition to this introduction. One paper is based on one of the keynote lectures, while the other eight papers demonstrate some of the themes and approaches in current Norwegian research on socioeconomic health inequalities. Most of the articles have been authored by researchers who are working on a doctoral thesis or have recently attained their doctoral degree. The papers cluster into four groups. One cluster has a common denominator in intervention and policies to reduce health inequalities. A second focuses on marginalised groups, whereas a third cluster draws attention to the possible impact of the social context on individual health. The last paper addresses health inequalities among adolescents. The main focus of the Soria Moria conference was how and why social health inequalities continue to exist in the Norwegian society with a long tradition of a social democratic welfare model. We are pleased to note that health inequalities are becoming a prioritised health policy issue in Norway, and hope this issue of the Norwegian Journal of Epidemiology will contribute to a sharper focus on monitoring of, research on, and interventions to reduce social inequalities in health.
\end{abstract}

\section{The Soria Moria Conference}

How and why do health inequalities exist in welfare states? This and other related questions were discussed during the research conference Health Inequalities and the Welfare State at the Soria Moria Conference Center in Oslo, Norway, October 10-11 2006. The conference was supported financially by the Research Council of Norway, NOVA - Norwegian Social Research, the Norwegian Directorate for Health and Social Affairs, Oslo University College, and the Norwegian Institute of Public Health. The main purpose of the conference was to support, stimulate, and disseminate social health inequality research in Norway. About one hundred scientists from different disciplines (social epidemiology, medicine, medical sociology, political science, economics, etc.) participated. The main focus of the conference was on the link between health inequalities, current social developments, and the welfare state. The conference included four distinguished keynote lecturers (Professor Johan Mackenbach, Netherlands, Professor George A. Kaplan, USA, Professor Johan Fritzell, Sweden, and Research Director Tone Fløtten, Norway). Nearly 40 papers by Norwegian researchers were presented.

The present issue of the Norwegian Journal of Epidemiology is based on this research conference. Professor Kaplan's keynote lecture is printed here, together with eight of the presented papers which demonstrate some of the themes and approaches in current Norwegian research on socioeconomic health inequalities.

\section{THE BACKGROUND}

There is a broad consensus that health in general, and health inequalities in particular, are dependent on how society is organised. Norway belongs to a group of countries which, according to Esping-Andersen (Esping-Andersen 1990), exemplify the Nordic welfare model. This model differs from other welfare state models such as the liberal (e.g. UK, USA) and the conservative (e.g. Germany, France) by several distinctive features (Kangas \& Palme 2005; Kautto et al. 2001). First and foremost, the idea of social rights implies that all citizens have universal access to relatively generous services and benefits. A large public sector, which also serves as an employment machine for women, is one characteristic, along with high employment rates, especially among women and the elderly. High employment is, among other things, a precondition for a broad tax base which is necessary for the financing of the comprehensive welfare state. Moreover, egalitarianism is a principal trait in the political culture, which corresponds to the fact that the wage structure is relatively compressed and that taxes and public transfers result in an even more egalitarian income structure. The Nordic welfare model has developed mainly since the 1930s, and its stated goals have been to provide uniform social protection and a democratic right to adequate living conditions for the whole population.

Thus, in the first decades of the post-war period, there was a widespread notion that Norway, alongside with other Nordic countries, had attained a society without distinct differences in social standing and 
living conditions. As a consequence, social inequality in health as a topic disappeared from the public debate, although some research reports during the 1970s demonstrated that the well-known patterns were still evident (Allern 1974; Haldorsen \& Glattre 1976). During the eighties and nineties social health inequalities gained increased attention. Results from an increasing number of studies (too many to be listed here) showed that inequality in health was considerably larger than first thought, even in the Norwegian society with a long tradition of a social democratic welfare model. Although the health of the Norwegian population generally is good and almost all groups in the socioeconomic hierarchy have experienced improved health over the past decades, the upper echelons of the socioeconomic ladder have had the most favourable development. Accordingly, there are indications that in Norway, socioeconomic health inequalities not only persist, but may even have increased during recent decades, at least in relative terms (Borgan 1996; Næss et al. 2007; Zahl et al. 2003).

This situation, in which the existence of considerable socioeconomic inequalities in health is increasingly acknowledged both by researchers and by the political authorities, was the background for the conference - and for this issue of the Norwegian Journal of Epidemiology.

\section{INTERNATIONAL AND NATIONAL POLICIES TO TACKLE HEALTH INEQUALITIES}

Several countries have developed coordinated and comprehensive policies to deal with health inequalities, for instance Sweden, the Netherlands, and the UK. Up to very recently, Norway has been a laggard, but this is about to change. Social inequality in health, mostly overlooked during the 1990 s, was highlighted in the white paper; Report No. 16 (2002-2003) to the Storting (the parliament) from the Ministry of Health in 2003 (HD 2003). As a follow-up, the Norwegian Ministry of Health and Care Services established the Norwegian Knowledge Centre for the Health Services, aiming, among other things, to gather more systematic information about population health and the functioning of the health services. In January 2005, the Directorate for Health and Social Affairs appointed an expert group on social inequality in health. The mandate of the expert group is to give advice to the authorities about the prevalence and causes of social inequalities in health, and furthermore to suggest possible interventions to reduce these inequalities. "The Challenge of the Gradient" - which is the title of the Directorate's plan of action (SHDir 2005) - provides the basis for this work. In February 2007, the Norwegian Ministry of Health and Care Services presented the white paper; Report No. 20 (2006-2007) to the Storting (the parliament) entitled "National Strategy to Reduce Social Inequalities in Health" (HOD 2007), with policy suggestions and guidelines for monitoring of and research on social inequalities in health.
Prior to this report, the focus in Norwegian health policies was primarily on individual health risks, on the health of specific disadvantaged groups, and on possible health implications of poverty. Now, we have witnessed a turn towards acknowledging that health inequalities form a social gradient that cuts across the entire population. Simultaneously, a clearer distinction between upstream, midstream and downstream factors has also been defined. These changes will be important for the formulation of prospective policies and interventions to reduce health inequalities.

\section{INTERNATIONAL RESEARCH ON HEALTH INEQUALITIES AND THE STATUS OF NORWEGIAN RESEARCH}

Since the 1980s, there has almost been an explosion of studies on health inequalities in many Western countries. Financial opportunities offered by international bodies like the EU and European Science Foundation have strongly stimulated scientific development, both in terms of enabling comparative research and in terms of developing and refining new theories and analytical perspectives. Thus, compared to a few years ago, research on health inequalities have become a vibrant and sophisticated field of research where different scientific disciplines meet and contribute. Several promising explanatory models and perspectives have been distinguished, e.g. the life course approach, the psycho-social model, (neo-)material explanations, and macro-social determinants. In some countries, research activity has been particularly strong and persistent, e.g. UK, the Netherlands, Sweden and Finland - and USA.

One cannot say that Norwegian research on health inequalities has been as extensive and broad as in these countries. Nevertheless, Norwegian researchers have participated in these endeavours, and a recent overview (Sund \& Krokstad 2005) shows that the contributions from our country are considerable and significant. This overview, together with what could be learnt at the Soria Moria conference and the papers presented there, can however give rise to some reflections on the status of Norwegian research on social health inequalities.

Norwegian health inequality research is mainly produced by committed researchers scattered around in Norwegian universities and research institutions. Their contacts have often been limited to their own institution. Sometimes there have been links to selected foreign researchers and institutions; a long-lasting Nordic collaboration has been especially significant. Cooperation between Norwegian researchers has often been sporadic, and communication between Norwegian milieus has been lacking. This obscure map of Norwegian health inequality researchers - who they are, what themes they engage into - was one reason why the Soria Moria conference was initiated. One of the main aims was to contribute to a higher level of integration.

Furthermore, as to the quality of Norwegian re- 
search within this field, it is mixed. High-quality data, competent craftsmanship and technical skills are often found. However, theoretical and methodological innovations and conceptual developments are, although not absent, hardly a distinguishing characteristic. It might be said that the role of Norwegian research to a large extent has been to empirically examine the questions, topics and problems launched by research centres abroad. This is of course an honourable activity, but strengthening the theoretical ambitions of Norwegian health inequality research ought to be more stressed in the future.

The cooperation of Norwegian researchers in international research settings is one important way of addressing this problem. Progress and development of theories and research questions will benefit from international collaborations. Furthermore, in order to develop Norwegian health inequality research and assert this research in an international context, a critical mass is needed. This means that research institutions must be sustainable and that a sufficient number of Norwegian researchers pursue these issues on a regular basis. A further development of Norwegian health inequality research along such lines is of vital importance.

As to funding, health inequality as a research theme has never been a separate research program in the portfolio of the Research Council of Norway. Instead, the theme has been merged with several other research themes, most recently in the Public Health Program, a program that has limited financial resources at its disposal. Perhaps this situation is about to change for the better with the implementation of the above mentioned "National Strategy to Reduce Social Inequalities in Health". We may claim that the funding sources are not abundant, and that this field should be prioritised higher. However, it cannot be said that good research projects have no chances of getting funded, and the Research Council of Norway is only one of the funding institutions for health inequality research.

The availability of data for pursuing health inequality research is, in an international comparative perspective, quite good, especially for the adult population. The system of personal identification numbers used in Norway entails a huge potential for linking high-quality Norwegian registries on health information with registries on educational attainment, disability pension, sickness absence etc. In addition, the interview surveys provided by Statistics Norway constitute rich data sources. Series of comprehensive county health surveys have also been conducted since the 1970s, with data ranging from postal questionnaires to medical examinations. Other data sources include various ad-hoc surveys initiated by specific research projects, or data constructed as part of international cooperative projects.

Themes related to the pervasive health inequality patterns have now been taken up by several researchers, and the endeavours are multidisciplinary. Researchers with a background in sociology, social medicine, public health, economics, geography, psychology, political science, and social anthropology are involved. As a result, research on health inequalities and related subjects has been growing steadily, indicated both by the number of Norwegian research reports and by more contributions to international (mainly English-language) scientific journals. The Nordic collaboration of researchers has importantly contributed to this. One could perhaps say that Norway's and the other Nordic countries' position as especially rich and egalitarian welfare states, implies that Nordic health inequality research has not too high international transfer value or vice versa. On the other hand, the Nordic welfare states also constitute a particular "laboratory" for research because risk factors and social determinants of health probably are more evenly distributed here than in most other countries in the world. Why social health inequalities in Norway (and in the other Nordic countries) persist at the same level as in Western European countries, at least when measured in relative terms (Mackenbach 2005), is therefore a particularly intriguing question to pursue also for the international research community.

\section{THE CONTENT OF THIS ISSUE}

The selection of papers included in this special issue is not a representative sample of the papers presented at the conference. Rather, as guest editors we wanted to show a diversity of themes, and also to disseminate papers that were suitable for publication in a journal like the Norwegian Journal of Epidemiology. Moreover, a particular aim was to provide a publishing opportunity for young researchers, and most of the articles have been authored by researchers who are working on a doctoral thesis or have recently attained their doctoral degree.

With the exception of the overview paper given by Kaplan, the papers are clustered into four groups. One cluster focuses on groups marginalised in relation to the labour market (Naper et al., Gjesdal et al.). A second cluster has a common denominator in interventions and policies to reduce health inequalities (Elstad et al., Hem et al., Jenum et al.). The third cluster draws attention to a theme which has caused a lot of stir in international research on health inequalities, namely the possible impact of the social context on individual health (Sund et al., van der Wel). Finally, the paper by Torsheim et al. forms a separate cluster and addresses a topic that has been studied less than deserved in Norway; health inequalities among adolescents.

\section{THE PAPERS}

The first paper in this issue of Norwegian Journal of Epidemiology is Kaplan's summary of his plenary speech at the conference. According to Kaplan, we need to address how material (or "neo-material") factors are patterned in middle and high income countries 
like Norway. In addition, the importance of income inequality, place of living, exposures over the lifecourse, and factors associated with marginalization when explaining health inequalities in rich welfare states are stressed. According to Kaplan, there is a solid empirical basis that suggests that health inequalities can be reduced by targeting low socioeconomic position, place-related opportunity structures and risks, the life course, and social marginalization. For instance, rather than seeking to understand the process by which social marginalization affects health, a decontextualized view in which it is the group itself and its patterns of behaviour and culture is often seen as generating the increased risk. The solution to such a misguided approach is to uncover the processes that lie submerged, like the bulk of an iceberg.

One of the welfare state's goals is to give its citizens, irrespective of their status, class or the market value of their labour and property, help and support in social situations which otherwise may lead to crisis. Social assistance, as the last safety net in the welfare state, is an example of this. Naper et al. found that the mortality of social assistance recipients was considerably higher than the mortality of the rest of the population - both for men and women. The age-adjusted hazard ratios (HR) for long term recipients $(\geq 6$ months) were about 5 and 4 for male and female recipients, respectively. The mortality of long term recipients was also markedly higher than that of short term recipients. The excess mortality was, according to the authors, explained by low income, education and marital status. Gjesdal et al. have studied the mortality patterns of a different disadvantaged group in the welfare state, i.e. disability pensioners. Compared to the rest of the population, the age-adjusted hazard ratios were 3.5 and 2.5 for women with early and late disability pension, and 4.3 and 3.3 among men. After adjustment for socioeconomic variables, the HRs were 2.9 and 2.2 for women, and 2.2 and 1.9 for men. These results led the authors to conclude that their findings indicated a strong impact of the medical factors underlying the disability pension decision, especially among women. The socioeconomic factors related to the status as a disability pensioner were also important.

Intervention and policies to reduce health inequalities is the main focus in the papers by Elstad et al., Hem et al. and Jenum et al. Elstad et al. have studied educational inequalities in mortality and the role of different causes of death for these differences. They found a strong association between mortality and education, with a gradually increasing gradient from those with the highest to those with the lowest education. This association was also evident for cause-specific mortality, but the different causes of death had differing slopes of the gradient. If death risk in the lowest educational groups had been equal to the observed death risk in the highest educational group, 43 percent (men) and 39 percent (women) of the actually occurring deaths 1994-2003 would have been avoided. More than half of the potentially avoided deaths occurred among those with basic education. Cardiovascular diseases represented 38 percent (men) and 35 percent (women) of the hypothetical avoided deaths.

Hem et al. have analysed the educational inequalities in causes of death considered amenable to health care in Norway. They found a systematic higher age adjusted hazard ratio for lower educational groups among men and woman both in causes considered amenable as well as non-amenable to health care. The effect sizes were comparable for amenable and nonamenable causes.

There is a lack of research on outcomes of interventions in Norway as well as in many other countries. However, the "Romsås in Motion Study" is an important exception to this. The paper by Jenum et al. is based on a community-based three year intervention to increase physical activity in a multiethnic urban district with high mortality rates and low socioeconomic status. The project was carried out in the period 20002003 in the urban districts of Romsås (intervention area) and Furuset (control area) in Oslo. The researchers found that the increase in physical activity was 9.5 percent, and that the proportion who increased their body mass was 50 percent lower in the intervention district as compared with the control district. Beneficial effects were seen for cholesterol/HDLcholesterol ratio, triglyceride levels, glucose, systolic blood pressure and daily smoking. The results were comparable for those with high and low education, and for westerners and non-westerners. The authors conclude that effective area-based public health initiatives should be an integrated part of the Norwegian strategy to reduce the social gradient in health.

Both nationally and internationally, studies of place and health have gained increased attention among researchers, and the importance of contextual factors for health is well known from many studies. We will here present two studies from different regions in Norway, dealing with the relative influence of individual and contextual factors for health and illness. Sund et al. have examined the relationship between neighbourhood social capital and self-rated health and depression in the Nord-Trøndelag county. They found that geographical variations in self-rated health and depression were largely due to the socioeconomic characteristics of individuals. Contextual social capital, expressed as the level of trust, was, however, found to be associated with depression and self-rated health at the individual level. van der $\mathrm{Wel}$ found, in Oslo, a clear association between social capital and health - even after controlling for individual factors like sex, age and socioeconomic status, but the association was reduced and rendered insignificant when other contextual factors in the neighbourhood (median income, income inequality and area educational level) were taken into account. These findings support the hypothesis that contextual factors related to income and education in the area of residence matter for individual health. 
Measuring health inequalities in childhood and adolescence is not an easy task. In the adult population, socioeconomic position can be related to own education, occupation or income. In childhood and adolescence, social position must in some way be based on parental social affiliation. Torsheim et al. have analysed the role of behavioural mediating factors in adolescent health inequalities. They found that adolescents with lowest socioeconomic status had higher odds for self-rated fair or poor health, compared to those with highest socioeconomic status. Controlling for behavioural factors resulted in a reduction of the odds ratios for self-rated health. The results were interpreted by the authors as partial behavioural mediation. The results from the study might thus indicate that behaviour can be an important mediating mechanism for socioeconomic differences in adolescent selfrated health.

\section{Conclusion}

Health inequalities are a challenge for health policy, both because they are unfair and because the potential of health in the population is not fully exploited. We are therefore pleased to observe, as discussed above, that health inequalities are becoming a prioritised issue at the political agenda in Norway. Hopefully this might lead to increased focus on monitoring of, research on and interventions to reduce social inequalities in health. We hope this issue of the Norwegian Journal of Epidemiology will be one contribution to this.

\section{ACKNOWLEDGEMENTS}

As guest editors, we want to thank all participants at the research conference Health Inequalities and the Welfare State in October 2006, and specifically each of the contributing authors to this issue. We also want to express our thanks to the Editor of the Norwegian Journal of Epidemiology, Trond Peder Flaten, for his assistance and professional help through the process. Furthermore, we want to thank the reviewers who have greatly assisted in improving the contributions: Anders Bakken, Øyvind Giæver, Astrid Grasdal, Bjørn Hvinden, Olle Lundberg, Rannveig Nordhagen, Øyvind Næss, Axel West Pedersen, Bjørn Heine Strand, Gunnar Tellnes and Steinar Westin. This issue of the Norwegian Journal of Epidemiology has been supported financially by NOVA - Norwegian Social Research, Oslo University College and the Norwegian Institute of Public Health.

\section{REFERENCES}

Allern S (1974). Klasse og alvorlig sykelighet [Social class and serious illness] Thesis. Oslo: Department of Sociology, University of Oslo.

Borgan JK (1996). Socioeconomic trends in differential mortality among middle-aged males in Norway 19601990. Yearbook of Population Research in Finland, 33: 73-81.

Esping-Andersen G (1990). The three worlds of welfare capitalism. Cambridge: Polity Press.

Haldorsen T, Glattre E (1976). Yrke og dødelighet 1970-73. Statistiske analyser 21 [Occupational mortality 197073. Statistical analyses no. 21]. Oslo: Statistics Norway.

HD (2003). Resept for et sunnere Norge. Folkehelsepolitikken. St.meld.nr. 16 (2002-2003) [Prescription for a healthier Norway. Public Health Policies]. Oslo: Helsedepartementet (Ministry of Health).

HOD (2007). Nasjonal strategi for å utjevne sosiale helseforskjeller. St.meld. nr. 20 (2006-2007) [National Strategy to Reduce Social Inequalities in Health]. Oslo: Helse- og omsorgsdepartementet [The Ministry of Health and Care Services].

Kangas O, Palme J, eds. (2005). Social policy and economic development in the Nordic countries. Houndmills, Basingstoke, Hampshire, UK: Palgrave Macmillan.

Kautto M, Fritzell J, Hvinden B, Kvist J, Uusitalo H, eds. (2001). Nordic welfare states in the European context. London and New York: Routledge.

Mackenbach JP (2005). Health inequalities: Europe in profile. Rotterdam: Erasmus MC, University Medical Center Rotterdam.

Næss Ø, Rognerud M, Strand BH, eds. (2007). Sosial ulikhet $i$ helse. En faktarapport. Rapport 2007:1 [Social inequality in health. Facts report]. Oslo: Folkehelseinstituttet [Norwegian Institute of Public Health].

SHDir (2005). The Challenge of the Gradient. The Norwegian Directorate for Health and Social Affairs' plan of action to reduce social inequalities in health. Oslo: Sosial- og helsedirektoratet [Norwegian Directorate for Health and Social Affairs].

Sund ER, Krokstad S (2005). Sosiale ulikheter $i$ helse i Norge - en kunnskapsoversikt [Social inequalities in health in Norway - Review of the knowledge]. Oslo: Sosial- og helsedirektoratet [Norwegian Directorate of Health and Social Affairs].

Zahl PH, Rognerud M, Strand BH, Tverdal A (2003). Bedre helse - større forskjeller. Rapport 2003:1 [Better health - wider differences]. Oslo: Folkehelseinstituttet [Norwegian Institute of Public Health]. 


\section{Gjesteredaktører}

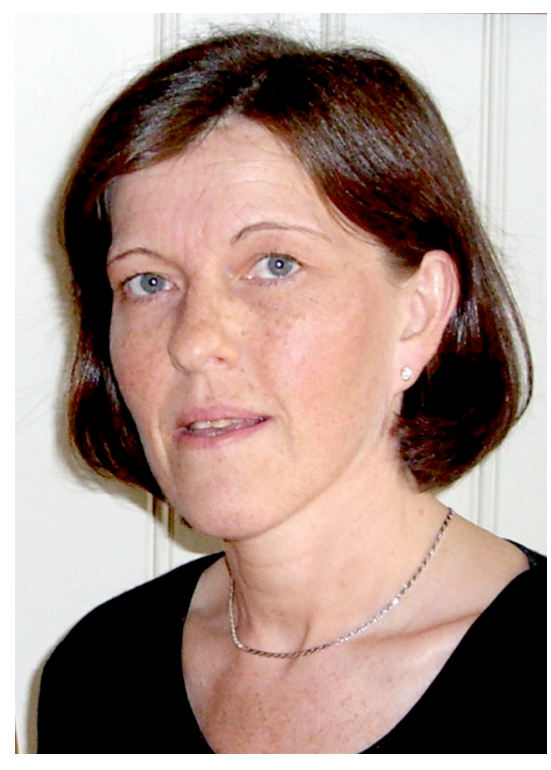

Else-Karin Grøholt

Nasjonalt folkehelseinstitutt else-karin.groholt@fhi.no

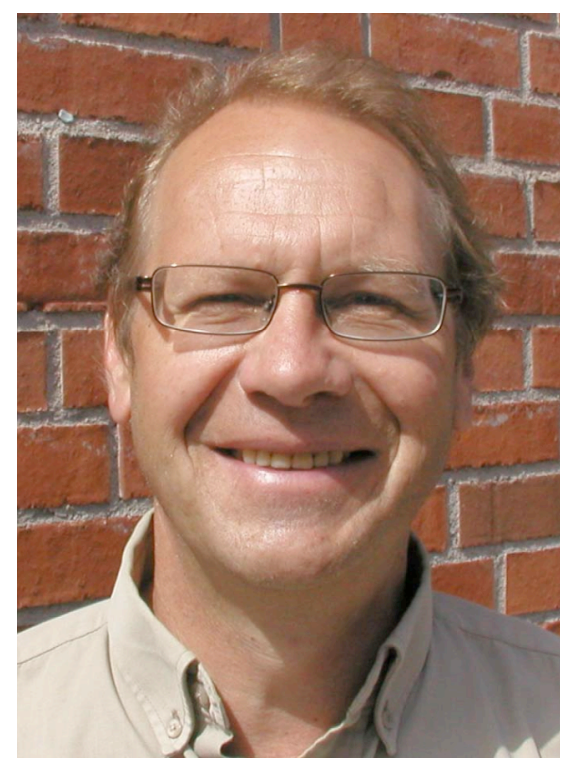

Espen Dahl

Høgskolen i Oslo

espen.dahl@hio.no

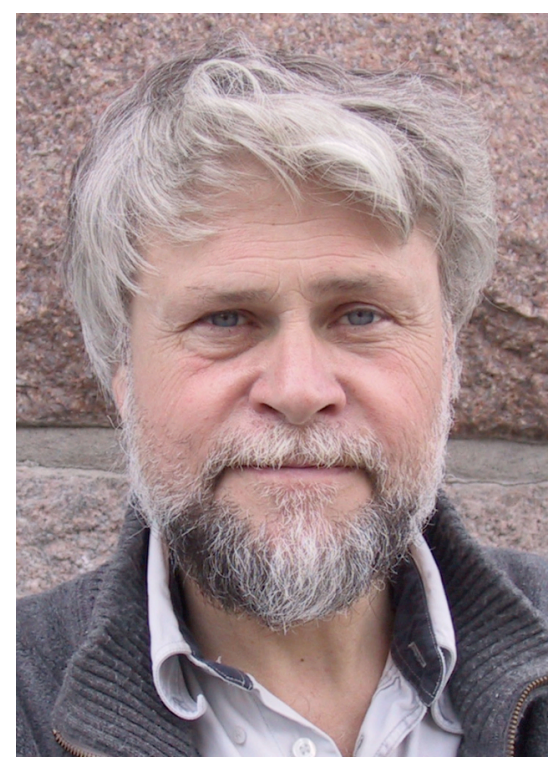

Jon Ivar Elstad

NOVA og Universitetet i Oslo

jon.i.elstad@nova.no 